\title{
Um estudo sobre a ontologia do espaço na obra de Martin Heidegger
}

\begin{abstract}
Resumo
Este artigo pretende contribuir com o estudo da ontologia do espaço na obra de Martin Heidegger. Para tanto, dentro das limitações deste trabalho, procuramos analisar os contornos da fenomenologia heideggeriana, apontando como o filósofo alemão pensa a sua filosofia enquanto uma alternativa à metafísica tradicional concebida na modernidade. O objetivo central, aqui, é pôr em discussão o sentido do homem enquanto ser-no-mundo, entendendo o espaço como uma categoria de análise de grande importância para o homem-no-mundo, para a sociedade e, portanto, para a ciência geográfica.
\end{abstract}

Palavras-chave: Espaço, Mundo, Ontologia, Fenomenologia, Geografia.

\begin{abstract}
A STUDY ON THE ONTOLOGY OF SPACE IN WORK OF MARTIN HEIDEGGER

This article aims to contribute to the study of the ontology of space in the work of Martin Heidegger. To do so, within the limitations of this work, we analyze the characteristics of Heideggerian phenomenology, pointing out how the German philosopher thinks his philosophy as an alternative to traditional metaphysics conceived in modernity. The main objective here is to focus discussion on the meaning of man as being in the world, understanding space as a category of analysis of great importance to man-in-the-world, to society and, therefore, for science geographical.
\end{abstract}

Key-words: Space, World, Ontology, Phenomenology, Geography. 


\section{Introdução}

O espaço, enquanto categoria de análise, nunca foi propriedade da Geografia. A filosofia grega já se debruçava sobre as questões espaciais, principalmente com as teorizações de Platão e Aristóteles. E, já nesse momento, o espaço se encontrava num campo repleto de limitações. Deste modo, os componentes da crise espacial foram os limites de análise do espaço embutidos ainda nas teorizações dos dois filósofos gregos citados.

Platão chega a falar em espaço como substrato físico ou matéria capaz de apreender todos os objetos em movimentação nele inseridos, servindo apenas como recipiente. Vale dizer que a Geografia enquanto ciência moderna resgatou a ideia de espaço de Platão para servi-la de base às suas proposições analíticas.

Aristóteles, por sua vez, critica o postulado platônico ao sugerir que o espaço possui uma limitação e, que, deste modo, não se poderia determinar seus limites, suas formas. Para o pensamento aristotélico, o ser é dividido em essentia e existentia. É dessa maneira que o espaço já é reconhecido como uma categoria em crise.

Eis que surge a possibilidade cartesiana de entender o espaço. Aqui, a concepção platônica é resgatada e, num processo de geometrização espacial, uma dicotomia patológica se instaura: a dicotomia entre o ser e o ente. E é nesse momento em que o filósofo alemão Martin Heidegger vai apontar, na obra Ser e Tempo, o que Ruy Moreira (2010) propôs chamar de mal-estar espacial no fim do século XX. Isto é, Heidegger vai tratar da separação do ente do ser, denunciando a modernidade e, principalmente, a metafísica tradicional, culpando-a pelo o que ele chamou de entificação do ser. Neste momento, o corpo se ocupava apenas de uma determinada parcela do espaço, não sendo ele mesmo espacial.

É importante, aqui, deixar claro que a dita separação entre o ente e o ser se dá na dicotomia originada pelas propostas da metafísica. Para Heidegger, a preocupação da filosofia estava apenas em unir ente e ser, dicotomizando-os, sem perceber que ambos fazem parte de um corpo só, de uma totalidade. Portanto, ser-ente, homem-mundo e sujeito-objeto precisam, cada um, encontrar sua unidade para que a filosofia retorne ao 
eixo da observação eficaz da ontologia, ainda que seja difícil detectar uma equivalência entre as partes.

A este respeito, Ruy Moreira (2010) explica que passa a ser evidente que o mundo-do-homem se separa do próprio homem, quando comenta Descartes e sua dicotomia entre espaço e homem ou, ainda, natureza (res extensa) e espírito (res cogitans), ademais quando menciona a física newtoniana que separa os entes corpóreos em corpos físicos e corpos vivos, este último significando o próprio corpo humano e, por fim, quando exalta a filosofia crítica de Kant, na qual o espaço funciona como um a priori à possibilidade de qualquer ontologia.

Afinal, como o espaço é concebido para Heidegger na obra Ser e Tempo? Qual sua importância e implicação dentro da crise da diferença ontológica $^{2}$ ? Este estudo pretende refletir sobre os esforços de Heidegger em clarificar a existência de um impasse filosófico, que acabou colocando-o distante do pensamento ontológico. Tudo isso objetivando uma reflexão sobre os impactos da fenomenologia heideggeriana nos estudos da ciência geográfica que, mais tarde, reconheceu este impasse filosófico e suas influências nas análises do espaço. E o que levou a este episódio foi, conforme aponta Claval (2003), a descoberta pelos geógrafos de uma geografia cultural nova, graças à preocupação de Armand Frémont, ainda em 1970, em formular uma geografia voltada para a experiência do homem com seu espaço, dando importância aos estudos das experiências vividas no lugar, criando, assim, uma corrente contrária àquela já estabelecida pelos geógrafos franceses, da exatidão, da observação e dos números. A partir daí, através das análises do espaço vivido, a fenomenologia de Heidegger ganha espaço na Geografia e, Eric Dardel, que desde os anos 1950 já insistia na abordagem própria de uma Geografia Existencial ao analisar a interação do homem com a Terra, "é enfim lido e apreciado" (CLAVAL, 2003, p. 13)

\section{Concepçães de mundo: ser-no-mundo, modos de ocupação e mundanidade}

(...) o mundo do Dasein é, acentua Heidegger, um mundo espacial. Não no sentido em que é espacial o mundo de Descartes e Newton (ou mesmo de Leibniz), um 
mundo de coordenadas frias e neutras. (...) Trata-se de um mundo em que as pessoas estão próximas ou distantes, mas no qual as distâncias não são medidas somente em milhas e quilômetros (...) (INWOOD, 2004, p. 51).

Heidegger foge de Descartes e Kant para entender o espaço. Para o filósofo, o espaço é, a priori, um não-lugar do homem e não está contido no mundo. $\mathrm{O}$ ato do ser, de compreender o mundo, é a busca deste mesmo ser por uma pre-sença que, por sua vez, significa ser constantemente. Portanto, estar sendo enquanto presença é reconhecer a sua existência. Mas não se trata, aqui, de considerar a existência de um ser qualquer e sim do ser-no-mundo. Esta expressão traduz uma totalidade ou unidade, nos termos de Heidegger. É o ser que deve necessariamente ser a priori de sua presença. Deste modo, pode-se falar em um ser-em numa totalidade já embutida no ser-no-mundo.

Ser-em significa negar uma (a)espacialidade do ente. Este termo rompe com as três leis geográficas surgidas com a diferença ontológica. São elas: desnaturização, desterreação e desterritorialização (MOREIRA, 2010). E mais, ser-em é o sujeito num mundo e dentro de um espaço específico. Portanto, mundo, espaço e ente constituem a unidade do ser-no-mundo, que é, grosso modo, a estrutura do homem. Este, em presença, compreende o mundo, pois passa a ser no mundo e a senti-lo. Isto, nos termos de Dardel (1952), é o espaço geográfico sendo compreendido pelo homem a partir de sua "geograficidade" (geographicité). É o momento em que o seu lugar é habitado, pensado e sentido, num consentimento provindo de sua experiência espacial e, portanto, de sua existência ${ }^{4}$. Esta experiência está contida numa trama complexa de possibilidades, que a torna positiva (topofilica) ou negativa (topofóbica).

Embora priorize a temporalidade ${ }^{5}$, a ontologia heideggeriana destaca a importância do espaço e de seu reconhecimento pelo ente. É curioso quando, por exemplo, o filósofo diz que ser "em algum lugar" não significa estar simplesmente "dentro de um lugar". O homem nunca é posto num espaço, como se estivesse sendo ordenado pela lógica espacial. Na verdade, o homem está "em algum lugar" porque o sente, o habita, o quer. É quando se reconhece enquanto homem, pois está familiarizado, acostumado com este ou aquele espaço. E quando isso se cumpre, "o Dasein, pelo simples 
fato de existir, segundo Heidegger, cria um espaço para seu campo de ação, e sendo assim, não pode ser compreendido enquanto um simples estar presente em algum lugar ("aqui"). O Dasein, nestes termos, configura novos lugares, ou seja, ele espacializa" (LEAL, 2010, p. 95).

Com isso, o ser-junto traduz não uma adesão do homem no mundo ou, como quer Heidegger, uma justaposição entre o ente em sua existência e o mundo. Este termo, originado no escopo do ser-em, remete a uma ideia de colaboração ou, talvez, união entre a presença e o mundo, ou seja, entre o ser-aí (homem) e o mundo. A presença, por sua vez, sendo ela como é, mostra-se dentro de uma possibilidade de ser, escolhendo o seu modo de ser. Isto sendo possível, podemos considerá-la como facticidade.

Facticidade é um conceito que abriga o ser e o ente, mas não ser e ente quaisquer. Ela abriga o ser-no-mundo da pre-sença e ente, agora intramundano. A facticidade projeta o ser-no-mundo da pre-sença à complexidade e às possiblidades dos modos de ser-em. É como se o homem estivesse precisando de um manejo ou um caminho no mundo para se colocar nele enquanto existência. E para que isso ocorra é preciso que o seu ser se encontre com os modos de ser que tenham o modo de ser da ocupação. Mas afinal, qual é o ser da pre-sença? Heidegger afirma ser a cura. Se o ser do ser-no-mundo é a ocupação, por pertencer à pre-sença, o ser da pre-sença é a cura, pois só a partir dela a pre-sença está no mundo.

Heidegger busca romper com a ideia de homem determinando o mundo e do mundo determinando o homem, como se ambos fossem elementos diferentes. Pelo contrário, as duas partes estão num só corpo e se complementam, num ideal constitutivo. O homem enquanto presença é aquele que reconhece o seu poder-ser no mundo, é o ente que possui um ser capaz de questionar. Daí o termo Dasein (ser-aí), tentando traduzir este caráter questionador do ser de um ente. O ser-aí exige uma explicação, interpela e não se submete à vontade mundana, pois ele não foi colocado no mundo. Portanto, ser em condição de ser-aí é questionar-se sobre o seu próprio ser, abrindo-se para o mundo e reconhecendo-o como seu lugar ou, nas palavras de Didier Franck (1986), como a "localidade mortalmente habitada" ou, ainda, a "região mortal da localidade". 
Deste modo, a abertura ("aí") do homem para o mundo não se constitui num simples acaso mundano ou de uma pretensa realidade, mas se contempla pelas possiblidades dadas pela existência. A respeito da existência, Vattimo (1989) argumenta que o termo "(...) no caso do homem, deve entender-se no sentido etimológico de ex-sistere, estar fora, ultrapassar a realidade simplesmente presente na direção da possibilidade" (p. 25).

E qual é o lugar do mundo na ontologia de Heidegger? O autor nos explica que é necessário analisar e entender o mundo para daí então poder falar do espaço, da espacialidade. Se o ser já é "aí" (ou seja, disposto à abertura), este é o ser-no-mundo que apreende o mundo como um modo de sua pre-sença. Só então poderíamos falar de espaço, já que antes o mundo era "externo" ao homem. O homem e o seu poder-ser, num tom de necessidade à questão do ser, se torna um ente exemplar e, pela presença existe e se dá, tornando-se um ente transcendente-imanente. Transcendente por já se encontrar no mundo, ter a sua existência em curso e imanente por ter, o ente, a possibilidade de ser.

O momento é oportuno para voltarmos aos modos de ocupação. Vimos acima que o ser do ser-no-mundo é a ocupação. Mas o que de fato isso significa para Heidegger? Em primeiro lugar, uma crítica à determinação de mundo interpretada por Descartes. Este, em sua análise, separa o ego cogito (sujeito pensante em existência) em dois corpos: res cogitans e res corporea. Mais tarde, esta dicotomia irá levar a outra, entre natureza e espírito. Em meio a essas dicotomias, Descartes reservou um termo para se referir ao ser de um ente: substantia. Este, nas aferições do próprio Heidegger, vai fazer referência tanto ao ser quanto ao ente. Para o ser, substantia irá apontar a substância do ser ou a sua substancialidade. E, para o ente, substantia será a sua própria substância.

Cada substância possui um atributo e é a partir dele que a mesma passa a ser conhecida, mensurada. Ora, o ser não pode ser explicado por atributos, mas pelos movimentos, pelo tecer de relações e de complexidades. Aí sim a pre-sença vai ao encontro a outros entes que não possuem o seu modo de ser. O movimento que se perpetua nesse emaranhado no ser da presença é chamado de cura, conforme visto anteriormente. E a cura é o modo como a presença se coloca no mundo, num diálogo concordante 
ou discordante em relação com os modos de ocupação dos outros entes. Heidegger, em Ser e Tempo, se dispõe a pensar na impossibilidade no ser-todo de um ente que, em sua existência, saboreia toda a esfera na feitura de ser de sua presença, isto é, pensar a totalidade da presença é encontrar-se com a inevitável pendência da cura. Ela, a cura, que indubitavelmente inscreve-se na totalidade da presença para diante de algo presente, "(...) que ainda não se tornou 'real', como um poder-ser de si mesma" (2009, p. 309-310).

Deste modo, a totalidade não se dá por ser incapacitada de considerar a insistente (in)conclusão no ato de formação da presença, sendo a não-totalidade uma pendência no poder-ser, assim colocado pelo filósofo. O que a pendência, a não-totalidade ou a insistente (in)conclusão demonstra é a impossibilidade de aflorar da presença sem que se dê a pendência. Quando esta mesma presença desmantela o algo pendente, já não mais se reconhece como tal, tornando-se o não-mais-ser-presença. "Retirar-lhe o que há de pendente significa aniquilar o seu ser" (2009, p. 310). O ente, portanto, não se realiza em totalidade quando ele mesmo se reconhece como presença. Do contrário, se formado em totalidade for, irá transmutar-se em um não-ser-no-mundo, ou ainda, cessará as possibilidades de se experimentar no mundo como um ente.

Em suma, a possibilidade da presença ser-toda entra em choque com a cura como totalidade da presença, pois no momento da cura o anteceder-a-si-mesma determina seu ser, o que acaba presumindo a presença por si mesma, com o seu poder-ser. Todavia, na construção/formação da cura encontra-se sempre um algo pendente ou uma pendência que ainda não se tornou real.

A não-totalidade encontra seu fim com a morte. O autor discute em três teses formulações sobre a morte: I- o pendente que se encontra na presença, o ainda-não. "A presença sempre existe no modo em que o seu ainda-não [que se mantém provisória e momentaneamente] lhe pertence" (2009, p. 317). O ainda-não está contido na presença, ainda que se mostre no plano "não-real". O fato é que o ainda-não não pertence ao exterior, porque já faz parte do próprio ser; II- o chegar-ao-fim ganhando a interface de não-ser-mais-presença, na superação de algo pendente; III- o chegar ao 
fim eliminando um determinado modo de ser, partindo da ideia de que este é insubstituível. Expõe Heidegger que "enquanto algo à mão, a soma incompleta é 'indiferente' ao resto que falta e não está à mão. Em sentido rigoroso, a soma não pode ser nem indiferente nem não diferente" (2009, p. 318).

A presença sendo ela mesma já é o ainda-não e o seu fim. Mas o que postula este fim não é, ou melhor, não significa estar-no-fim. Cabe ressaltar que o fim da presença não se capta pelo findar (pelo dado e terminado). "Na morte, a presença nem se completa, nem simplesmente desaparece, nem acaba e nem pode estar disponível à mão" (2009, p. 320). A presença enquanto permanência é o seu ainda-não e o seu fim. "O findar implicado na morte não significa o ser e estar-no-fim da presença, mas o seu ser-para-o-fim" (2009, p. 320). A morte, deste modo, é o comportamento da própria presença que se faz conhecer no momento em que é.

Heidegger indica que, ao tomar ciência da existência e permanência do ser-para-o-fim, elucida-se a visão de totalidade da presença, "desde que essa totalidade seja constituída pela morte, entendida como 'fim'” (2009, p. 320), pois, lembrando o já visto, a presença conhece a si mesma numa não-totalidade, podendo esta se afirmar a partir do reconhecimento de que uma pendência no poder-ser exista. A totalidade não corporifica os códigos que a pendência controla ou possui, porque a (in)conclusão ou a pendência significa as possibilidades do ser e do seu poder-ser.

Numa não-totalidade, a presença é convocada ainda que pela pendência, mas o pendente não elimina as possibilidades do ser, pelo contrário. Ainda que uma de suas partes esteja na (in)conclusão, o ainda-não apenas funciona como elemento constitutivo do ser. "O ainda-não já está incluído em seu próprio ser, não como uma determinação arbitrária e sim como um constitutivo" (2009, p. 318).

O ser-no-mundo existindo na presença não está apto para conhecer a disposição da morte com o ser, nem mesmo sabe que ela a pertence. É através da angústia que o ser-no-mundo recebe essa informação. "Para a presença, o fim é impendente. A morte não é algo simplesmente ainda-não dado e nem o último pendente reduzido ao mínimo, mas muito ao contrário, algo impendente, iminente" (HEIDEGGER, 2009, p. 325). A 
morte é algo impendente porque vem ao encontro no mundo, a partir das "possibilidades ontológicas próprias, que se fundam no ser-com os outros" (p. 326). A angústia, aliás, é tida como algo essencial para a origem da existência, pois ela "revela toda a problemática do ser" (BITETI, 2007, p. 92).

Em segundo lugar, Heidegger analisa os modos de ocupação para explicar o modo com que o homem-no-mundo se deleita através da ocupação. Ele só ocupa, só existe, quando se relaciona com os entes e só se organiza a partir da geograficidade do próprio homem-no-mundo. Daí Moreira (2004) afirmar que:

A geografia pode ser definida como a atitude de representação e reflexão analíticas do homem-no-mundo, a partir do modo como este nele organiza sua relação com a sociedade e a natureza - portanto consigo mesmo - no vir-a-ser do processo evolutivo da história. Refere-se, pois, à contextualização e existencialidade - diremos à geograficidade - espacial do homem no mundo, condição que difere aqui e ali de acordo com as estruturas da história (22-23).

Esta existencialidade (MOREIRA, 2004) pode ser empreendida sob o aspecto que Armando Corrêa da Silva (1978) vai desenvolver a partir do espaço relacional de Harvey: "(...) o espaço é o ser, através do qual as determinações da existência, a existencialidade, são as possibilidades ontológicas deste ser (o espaço)" (apud GUIMARÃES, 2009, p. 32).

As escolhas que eventualmente surgem, torna o ser-aí disposto e capaz de conquistar uma posição nova na totalidade do mundo. Esta mesma totalidade, agora como categoria, pode ser interpretada como potência. Daí Guimarães (2009) destacar que:

(...) A totalidade é o ser como potência, a essência universal dos entes, desde seu especulado 'momento primevo'. Então temos o ser enquanto essência, aquilo que pelo qual uma coisa é o que ela é (uno e potência), e o ser enquanto existência, o que confere à essência o ato de existir (múltiplo e ato) (p. 36).

A organização com a qual o ser-no-mundo se torna no espaço, esclarece-nos que a obtenção desta ação se projeta mediada ao encargo de sempre ocupar-se de alguma coisa, mesmo que pelo "ócio, lassidão, o dês-compromisso ou a renúncia de tarefas (...)" (KAHLMEYER-MERTENS, 2008, p. 175). Desta maneira, poder-se-ia destacar que a manualidade acaba por apresentar os utensílios como os são (ser-em-si), de modo que os ma- 
nuais são responsáveis por sua estruturação - agregam valor ou qualidade de ser útil, de ter utilidade. Estes manuais (utensílios) anunciam os entes que se manifestam desde o momento em que a ocupação se dá, se mostra ou "daquilo que podemos tratar como paradigma do uso" (KAHLMEYERMERTENS, 2008, p. 176).

Cabe dizer que o encontro dos entes com o ser-no-mundo é pré-temático ou pré-tematicamente apresentado. Isso quer dizer que o ser-no-mundo não reconhece os entes como "coisas capazes de sustentar qualidades ou propriedades verificáveis por meio de um conhecimento que, em seu modo de ser, já seria reflexivo" (KAHLMEYER-MERTENS, 2008, p. 175). Nas palavras de Heidegger:

\footnotetext{
O ente que assim nos vem ao encontro é visualizado pré-tematicamente por um 'conhecimento' que, sendo fenomenológico, aspira primordialmente o ser e partindo dessa tematização do ser, tematiza igualmente o ente em sua causa. Essa interpretação fenomenológica não é, pois, um conhecimento de propriedade entiativas dos entes, mas da estrutura de seu ser (HEIDEGGER, 2009, p. 108).
}

Em Moreira (2004) temos a mundanidade como "o sentido da própria ação geográfica do homem em sociedade na história. Vale dizer, a dimensão ontológica" (p. 28). O autor destaca o ser-estar-do-homem-no-mundo como o próprio espaço, o modo como o homem-no-mundo organiza suas estruturas na sociedade e natureza ou ainda, a maneira como o homem se põe no mundo e em sua relação com ele mesmo.

O ser-aí, ou mesmo sua presença, se torna na medida em que sua geograficidade se estende e se conhece no mundo. No limiar da convergência das ontologias, esta espacialização corrobora para o estabelecimento e a permanência do ser-estar do homem no mundo - evocando Hegel - ou ainda, a própria mundanidade de Heidegger já explicitada (MOREIRA, 2004). Esta geograficidade, nas aferições de Dardel (1952), é o vetor de realização do elo entre a Terra e o homem, a partir de sua própria existência. Para o autor, o espaço não é um esteio por onde os episódios vêm à luz. Pelo contrário, o espaço assume seu caráter fundamental com o homem, pois passa a se configurar como o lugar do homem e sua possiblidade enquanto homem-no-mundo em presença. Cabral (2000) ao comentar a geograficidade de Dardel explicita que ela "inclui os bons e os maus encontros com 
os ambientes e, possivelmente, a atração por um e o desagrado pelo outro adquiram suas forças qualidades através da comparação" (p. 41).

E os entes que não possuem o modo de ser da presença? Para estes, Heidegger reservou um termo: entes intramundanos ${ }^{6}$. O ser-no-mundo não se torna espacial no mundo e escolhe um local exclusivo para si, se isolando dos entes intramundanos. Na verdade, não existe essa ideia de localização delimitada entre os entes intramundanos e o ser-no-mundo. O que existe é uma teia relacional ou rede que se compreende na chamada cotidianidade mediana, termo designado aos costumes, aos hábitos comuns que são mensuráveis no cotidiano.

Não é objetivo nosso investigar como os entes intramundanos se articulam com a presença, mas é importante deixar evidente sua existência. Estes entes, aliás, ajudam-nos a compreender a espacialidade da ocupação de que vínhamos falando. A este respeito, Canário (2005) destaca que

\begin{abstract}
a espacialidade da ocupação diz respeito prioritariamente ao ser-em da pres-ença, onde esse em deve ser entendido, então, como conjuntura. Isso quer dizer que a totalidade referencial, que já se viu ser condição para o ente vir ao encontro, tem que ser liberada pela pres-ença (p. 35).
\end{abstract}

Portanto, "pres-ença só é enquanto deixar e fazer com que algo já se tenha liberado numa conjuntura" (CANÁRIO, 2005, p. 35). Essa conjuntura, juntamente com os entes intramundanos, é descoberta somente a partir da totalidade conjuntural. Pensar na existência da presença é fazer um esforço para pensar no papel do comportamento do próprio ser-no-mundo, pois, se a presença está fora, a disposição do ser-em no mundo já supõe a abertura da presença. "Pode-se dizer, então, que a pres-ença se constitui como abertura" (CANÁRIO, 2005, p. 36).

Estamos, por fim, a ponto de responder a seguinte questão: o que constitui a mundanidade do mundo? A presença estando no mundo, a partir de sua abertura e mediante o "auxílio" do ser-no-mundo, inicia a fase de sua compreensão. Este processo é o modo como a presença começa a sentir o mundo. É a partir deste fenômeno que a presença se encontra com os entes intramundanos. Daí Heidegger tratar disto como uma perspectiva da presença em formação. Eis a estrutura necessária para a origem da mundanidade do mundo. 


\title{
3. Espaço: espacialidade, região e circumundanidade
}

\begin{abstract}
O homem está superando as longitudes mais afastadas no menor espaço de tempo. Está deixando para trás de si as maiores distâncias e pondo tudo diante de si na menor distância. E, no entanto, a supressão apressada de todo distanciamento não Ihe traz proximidade. Proximidade não é pouca distância. O que, na perspectiva da metragem, está perto de nós, no menor afastamento, como na imagem do filme ou no som do rádio, pode estar longe de nós, numa grande distância.

E o que, do ponto de vista da metragem, se acha longe, numa distância incomensurável, pode-nos estar bem próximo. Pequeno distanciamento ainda não é proximidade, como um grande afastamento ainda não é distância (HEIDEGGER, 2001, p. 143).
\end{abstract}

Entender a espacialidade do ser-aí no mundo é, indubitavelmente, afirmar que sua localização não se verifica pelos procedimentos geométricos, ou seja, pelo modo como o postulado cartesiano pensa a localização. Este conjunto de métodos para aferir a localização do ser-aí é indiferente, pois "a aproximação não implica necessariamente uma proximidade física das coisas, posto que o 'aqui' não envolve uma localização simplesmente dada; o 'aqui' do Dasein significa antes estar junto de" (LEAL, 2010, p. 96-97).

O curioso, portanto, é perceber como Heidegger pensa a espacialidade do ser-aí. O que concebe a presença é o encontro e não o posto, o posicionado. O mundo é compreendido pela presença e não medido, achado e habitado arbitrariamente. Os modos de ocupação são aqueles que convidam o Dasein ao encontro com o mundo, diferentemente do pensamento cartesiano, que entifica o ser e trata-o como coisa espacializada. Um encontro propiciado pela referencialidade, pois é o que torna o Dasein capaz de descobrir e compreender os intramundanos. Este encontro, para Heidegger, permite o Dasein dar-espaço para que sua espacialidade se ponha em andamento.

A presença em sua mundanidade, em sua estrutura ser-no-mundo, já consegue conceber sua espacialidade originária, mas não tomando isto como um processo isolado da espacialidade dos intramundanos que, como já visto, se encontram com a presença no vir-a-ser em sua ocupação cotidiana. Este último processo já é a espacialização do Dasein que, tomando 
os entes intramundanos como manualidade, encontra-os e os toma como instrumento. Canário (2010) afirma que "o instrumento pertence a essa conjuntura que, em se tratando da espacialidade da ocupação, chama-se região" (p. 41).

O termo região insinua um punhado de possibilidades trazidas pelos entes intramundanos, agora como instrumentos. Além disso, sugere, através da ocupação, uma visão ou circunvisão do espaço, não mensurável e não disposto a uma construção cartográfica. Além da região, os entes intramundanos trazem à mão uma conjuntura regional (CANÁRIO, 2010, p. 41). Esta conjuntura dispõe à mão locais específicos ao Dasein. Heidegger pensa a região como o destino do Dasein (para onde), o seu caminho.

O filósofo trata os entes intramundanos ("coisas") como lugares espaciais que especializam os não-lugares, dito de outra forma, os vazios. Nas palavras do autor, "as coisas são lugares que propiciam espaços" (HEIDEGGER, 2001). Portanto, sendo o intramundano um lugar espacial capaz de propiciar espaços, a presença, sendo ser-no-mundo, se espacializa numa rede de lugares que poderíamos chamar de região. Por ser ela um campo por onde o lugar deve estar (pois o lugar está sempre dentro de uma possibilidade regional), o Dasein se estabelece mediante sua capacidade de aproximação. Se o ser-aí possui essa característica de aproximação, a presença é, portanto, espacial.

A compreensão daquilo que Heidegger designa como a 'espacialidade originária' do ser no mundo constitui uma etapa essencial para qualquer abordagem mais aprofundada da relação entre o Dasein e o espaço. Nesse sentido, o ser-no-mundo apresenta dois caracteres constitutivos: o distanciamento (Ent-fernung), aqui compreendido como poder de aproximação, e o direcionamento (Ausrichtung). Esses dois traços essenciais da espacialidade do Dasein não foram indicados de forma arbitrária: eles refletem não apenas sua tendência genuína para a proximidade - identificado que é com um mundo que se determina basicamente por seus envolvimentos -, mas refletem também o 'para onde' inerente ao seu estar permanentemente lançado para fora de si (SARAMAGO, 2008, p. 91).

Finalmente, o espaço em Heidegger é a grande descoberta do homem. Mas este só descobre o espaço quando toma a presença como seu constitutivo, enquanto estrutura ser-no-mundo. Simplificadamente, o sujeito não visualiza o mundo numa dimensão espacial, pois ele (o mundo) não está contido no espaço. Portanto, o sujeito e o mundo não estão no espaço. 
No entanto, sendo o homem ser-no-mundo, o espaço, como um a priori, é descoberto. Isso porque é a própria presença que possui um sentido espacial. Analisando o fenômeno do espaço, Heidegger afirma que

o espaço só pode ser concebido recorrendo-se ao mundo. Não se tem acesso ao espaço, de modo exclusivo ou primordial, através da desmundanização do mundo circundante. A espacialidade só pode ser descoberta a partir do mundo e isso de tal maneira que o próprio espaço se mostra também um constitutivo do mundo, de acordo com a espacialidade essencial da presença, no que respeita à sua constituição fundamental de ser-no-mundo (2009, p. 168).

A respeito da localização do homem-no-mundo, Dardel (1952), numa tentativa de resgatar a filosofia em seus estudos geográficos, pensa o afastamento (ou distância) e a direção como elementos de uma espacialização cotidiana, levando em consideração que dirigir-se e afastar-se são movimentações próprias da necessidade do homem em se conhecer e reconhecer os espaços que são tidos como "um pouco mais que vazios entre objetos" (RELPH, 1979, p. 21). Essa dita localização se confunde com o próprio lugar, se tomada como localização das atividades do homem (RELPH, 1979, p. 21). Sobre as direções, Dardel argumenta que

(...) foram então fixadas, elas também, por necessidades práticas. Ao mesmo tempo que procura tornar as coisas próximas, o homem necessita se dirigir, por sua vez, para se reconhecer no mundo circundante, para aí se encontrar, e para manter reta sua caminhada e para abreviar as distâncias. Um homem expatriado é um homem 'desorientado'; hesitar é, em todos os sentidos, hesitar sobre a direção a tomar (DARDEL, 1952, p. 14).

A partir dessas ponderações, Dardel passa a refletir sobre o espaço primitivo, uma necessidade de pensar um espaço único, que consiga interpretar o ponto de referência do homem-no-mundo, num exercício fundamentalmente existencial. Ponto de referência este que "é o próprio corpo e o suporte onde ele [o homem] se instala: a casa da família, a vila natal, as colinas. A partir dessas lembranças afetivas e imaginárias surge a linguagem geográfica (...)" (HOLZER, 2003, p. 119). O espaço primitivo é o chão da própria existência, o espaço que se estende até os contornos do espaço geográfico concreto, sendo ele "concreto e qualitativo, próximo e claro" (DARDEL, 1952, p. 17). 
Ademais, a distância e a direção são também importantes elementos para se entender o que Dardel chamou de situação, a base estrutural que condiciona a experiência do mundo a pôr em curso suas possibilidades. Situação é, portanto, a conjuntura favorável para que o homem consiga estabelecer o seu lugar no mundo.

\section{Considerações Finais}

Neste estudo, procuramos levantar algumas proposições da fenomenologia heideggeriana, entendendo-a como uma importante contribuição para a Geografia, no sentido de analisar a validade ontológica do espaço. No período da modernidade, a ciência geográfica estudava o espaço respaldada nos postulados condenados pelo filósofo alemão, ou seja, entendia-o "a partir de uma concepção teórica cartesiana-newtoniana-kantiana de espaço, que Armando Corrêa da Silva qualificou como um impasse, a saber, o impasse aristotélico-kantiano" (LEAL, 2010, p. 65).

O pensamento de Heidegger foi pouco explorado nas reformulações da Geografia que ocorreram no pós-1945 na França, Inglaterra e nos Estados Unidos. Seu pensamento passou por uma força contrária de resistência e, talvez, de repúdio. Só a partir dos anos 1970 que a fenomenologia heideggeriana passou a fazer parte dos estudos dos geógrafos, por intermédio de Edward Relph $(1973,1985)$, através dos seus estudos sobre a paisagem e o lugar. Relph procurou desenvolver uma nova Geografia respaldada nos conceitos heideggerianos, como habitar, identidade e diferença, "os quais oferecem ao autor uma base experiencial de compreensão da identidade dos lugares, estendendo-se assim ao binômio autenticidade-inautenticidade, do qual Relph também bebeu da fonte heideggeriana" (MARANDOLA JR., 2009, p. 4-5).

No Brasil, a proposta de uma ontologia geográfica só foi pensada nos anos 1970, justamente para a Geografia romper com este impasse em seu objeto de estudo, o espaço ${ }^{7}$, embora alguns geógrafos clássicos já haviam tentado travar um diálogo com a ontologia, visando uma busca pela compreensão da relação entre o homem-no-mundo e o espaço ${ }^{8}$. No entanto, 
apesar do dito movimento de renovação crítica ter tido como proposta a superação desses impasses e das crises teórico-epistêmicas, a Geografia ainda necessita repensar a(s) sua(s) metodologia(s) de pesquisa para não cair no erro em se tornar uma ciência fundamentada no pensamento peremptório.

\section{Notas}

${ }^{1}$ Integrante do Grupo de Estudos e Pesquisas sobre o Território e bolsista de Iniciação à Docência da UERJ, vinculado ao projeto de pesquisa "O território e a contemporaneidade: possibilidades de leitura da realidade e sua aplicabilidade no ensino de Geografia".

2 "A reflexão sobre a diferença inicia-se com a 'diferença ontológica', de Heidegger (1988), entendida como a relação de distanciamento entre o ser e os entes. Uma relação de irredutibilidade do ser no ente, que se traduz como ausência-presença" (MOREIRA, 1999, p. 45).

${ }^{3}$ Reconhecemos a aproximação de alguns geógrafos clássicos com os estudos ontológicos, como Paul Vidal de La Blache, Sorre e Pierre George, "a partir da caracterização da contingência, da complexidade e da existência, temas que aparecem respectivamente relacionados a cada autor" (BITETI, 2007, p. 1). E outros, num movimento de busca por uma Geografia Existencial, como Sauer (1925) que, ao inaugurar a Geografia Cultural, chegou a investigar uma fenomenologia da paisagem; Relph que, em sua tese The Phenomenon of Place (1973), apresentou à geografia norte-americana as formulações de Eric Dardel (1952); Anne Buttimer nos livros Nature, water symbols, and the human quest for wholeness (1985) e Grasping the dynamism of lifeworld (1976), ao travar um diálogo vivo com Heidegger para entender a Geografia a partir da fenomenologia; e, no século XIX, o geógrafo anarquista francês Élisée Reclus. No entanto, foi a partir das investigações de Eric Dardel (1952) que a Geografia se aproximou decisivamente da filosofia e, portanto, da fenomenologia heideggeriana.

${ }^{4}$ Eric Dardel se dispôs a ver no espaço uma condição de determinação do homem enquanto existência. O geógrafo francês procurou romper com as teorizações positivistas do espaço para tentar perceber a sua relação com o ser-no-mundo. A este respeito, Dardel argumenta que "la géographie n'est pas en son príncipe une connaissance; la réalité géographique n'est pas d'abord un 'objet'; le espace géographique n'est pas un espace en Blanc à remplir ensuite par coloriage. La Science géographique présuppose que le monde soit compris géographiquement, que l'homme se sente e se sache lié a la Terre comme être appelé à se réaliser en sa condition terrestre" (DARDEL, 1952, p. 46).

${ }^{5}$ Heidegger, em sua obra, dá uma importância à espacialidade, mas dá um destaque maior à temporalidade. Isso se deve ao fato de que, na busca pela existência autêntica, o homem não a consegue somente pela espacialidade. Na verdade, é através da temporalidade que o homem consegue cuidar das coisas e dos outros, a saber, dos outros entes.

${ }^{6}$ Os entes intramundanos são chamados de utensílios ou instrumentos, pois, no contato com a presença, os servem de alguma forma (como objeto de uso, de contemplação). Segundo Canário (2005), "eles não se desvelam como coisas simplesmente dadas à vista da pres-ença, mas sim como algo à mão, por isso o ser desses entes é designado manualidade” (p. 29).

7 "Tematizada desde os anos setenta, junto com o movimento de renovação que se convencionou chamar de geografia crítica, a busca da formulação de uma ontologia geográfica tem seu momento seminal mais permanente a partir dos textos de Armando Corrêa da Silva no Brasil. Silva se dedica a este tema em diferentes textos nos anos 1970 e 1980, a que se dedicam também outros geógrafos brasileiros" (BITETI, 2007, p. 138-139).

204. GeoTextos, vol. 8, n. 1, jul. 2012. B. Coutinho. 189-206 
8 "Um exemplo utilizado por Silva, advindo da geografia social francesa, e que serve para ilustrar o modo como a ontologia esteve presente entre os clássicos, está no pensamento de Élisée Reclus, que, em sua mencionada obra 'L'homme et la terre', apreende o espaço como determinando ontologicamente o real. Assim, dá-se uma resposta teórica às questões teóricas que precisam ser resolvidas no âmbito da geografia num momento de debate paradigmático e para além da necessária ação política" (BITETI, 2007, p. 141).

\section{Referências}

BITETI, M. O. Uma reflexão sobre o tema da ontologia na geografia, 164 p. 2007. Dissertação (Mestrado em Geografia Humana) - Programa de Pós-Graduação em Geografia, Universidade Federal Fluminense, 2007.

CABRAL, L. O. A paisagem enquanto fenômeno vivido. GEOSUL, Florianópolis, v. 15 , n. 30, p. 34-45. 2000.

CANÁRIO, L. P. O Lugar do Espaço em Ser e Tempo, 115 p. Dissertação (Mestrado em Filosofia) - Faculdade de Filosofia e Ciências Humanas, Universidade Federal da Bahia, 2005.

CLAVAL, P. A evolução recente da geografia cultural de língua francesa. GEOSUL, Florianópolis, v. 18, n. 55, p. 7-26. 2003.

DARDEL, E. L'Homme et la Terre: nature de la réalité géographique. Paris: Presses Universitaires de France, 1952. 133 p.

FRANCK, D. Heidegger e o problema do espaço. Lisboa: Instituto Piaget, 1986. 163 p.

GUIMARÃES, H.G. Ensaio sobre o espaço como modalidade ontológica do ser: nos caminhos de Armando Corrêa da Silva. Revista Discente Expressões Geográficas, Florianópolis, ano V, n. 05, p. 31-48. 2009.

HEIDEGGER, M. Ensaios e Conferências. Petrópolis: Vozes, 2001. 270 p.

. Ser e Tempo. 4. ed. Petrópolis: Vozes, 2009. 598 p.

HOLZER, W. O conceito de lugar na geografia cultural-humanista: uma contribuição para a geografia contemporânea. GEOgraphia, Niterói, v. 5, n. 10 , p. 113-123. 2003.

INWOOD, M. Heidegger. São Paulo: Edições Loyola, 2004 (Coleção Mestres do Pensar). 176 p. 
KAHLMEYER-MERTENS, R. S. Como Heidegger interpreta o começo da Metafísica em Ser e Tempo? Ítaca - Revista de Pós-Graduação em Filosofia do IFCS UFRJ, Rio de Janeiro, n. 9. p. 174-181. 2008.

LEAL, F. M. Coordenadas geográficas: ser-no-mundo, 140 p. Dissertação (Mestrado em Geografia Humana) - Faculdade de Filosofia, Letras e Ciências Humanas, Universidade de São Paulo, 2010.

MARANDOLA JR., E. Heidegger como matriz do pensamento fenomenológico em Geografia. In: II ENCONTRO NACIONAL DE HISTÓRIA DO PENSAMENTO GEOGRÁFICO, 2009, São Paulo. Anais. São Paulo : DGEO/USP, 2009.

MARTINS, E. R. Geografia e Ontologia: o fundamento geográfico do ser. GEOUSP - Espaço e Tempo, São Paulo, n. 21, p. 33-51. 2007.

MOREIRA, R. O mal-estar espacial no fim do século XX. In: MOREIRA, R. Pensar e Ser em Geografia. São Paulo: Contexto, 2010. 188 p.

. Marxismo e Geografia: a geograficidade e o diálogo das ontologias. GEOgraphia, Niterói, v. VI, n. VI, p. 21-38. 2004.

. A Diferença e a Geografia (o ardil da identidade e a representação da diferença na Geografia). GEOgraphia, Niterói, v. 1, n. 1, p. 25-42. 1999.

RELPH, E. As Bases Fenomenológicas da Geografia. Geografia, Rio Claro, v. 4, n. 7, p. 1-25. 1979.

SARAMAGO, L. A topologia do ser: lugar, espaço e linguagem no pensamento de Martin Heidegger. Rio de Janeiro: Ed. PUC-Rio; São Paulo: Ed. Loyola, 2008. $340 \mathrm{p}$.

VATTIMO, G. Introdução à Heidegger. Trad. Portuguesa de João Gama. Lisboa: Edições 70. 1986.

Recebido em: 05/01/2012

Aceito em: 10/03/2012 